\title{
Surgical and Conservative Management of Symptomatic Leiomyomas during Pregnancy: a Retrospective Pilot Study
}

\section{Operatives und konservatives Therapiemanagement von symptomatischen Leiomyomen in der Schwangerschaft: eine retrospektive Pilotstudie}

Authors

Affiliations
R. Rothmund ${ }^{1}$, F. A. Taran ${ }^{1}$, B. Boeer ${ }^{1}$, M. Wallwiener ${ }^{2}$, H. Abele ${ }^{1}$, R. Campo ${ }^{3}$, D. Wallwiener ${ }^{1}$, S. Brucker ${ }^{1}$, K. Rall ${ }^{1}$

1 Women's Clinic, University Tübingen, Tübingen

2 Women's Clinic, University Heidelberg, Heidelberg

${ }^{3}$ Leuven Institute for Fertility and Embryology, Leuven, Belgium

\section{Key words \\ - symptomatic leiomyomas pregnancy \\ - myomectomy \\ - degenerating leiomyoma \\ Schlüsselwörter \\ - symptomatische Leiomyome Schwangerschaft \\ - Myomektomie \\ - nekrotisierende Leiomyome}

received 11.12.2012

revised 11.3 .2013

accepted 12.3.2013

\section{Bibliography}

DOI http://dx.doi.org/

10.1055/s-0032-1328437

Geburtsh Frauenheilk 2013; 73:

330-334 @ Georg Thieme

Verlag KG Stuttgart · New York . ISSN 0016-5751

\section{Correspondence}

\section{Dr. Florin Andrei Taran}

University Tübingen

Women's Clinic

Calwerstraße 7

72076 Tübingen

florin.andrei.taran@gmail.com

\section{Abstract \\ $\nabla$}

Purpose: Evidence regarding distinguishing characteristics of women with symptomatic leiomyomas during pregnancy who undergo myomectomy during pregnancy and those who respond to conservative treatment is sparse because it mostly derives from case reports and small patient series. As the first of its type, the present study analyzed the characteristics of women with symptomatic leiomyomas treated with myomectomy during pregnancy and those treated conservatively.

Methods: We performed a computer search of medical records from 1 January 2001 to 31 March 2011 using the International Classification of Diseases Codes for pregnancy, myomectomy and leiomyomas during pregnancy.

Results: 27 patients were admitted during pregnancy directly related to leiomyomas; 17 of the 27 patients received conservative treatment for symptomatic leiomyomas, and 10 patients had surgery during pregnancy: 3 had undergone diagnostic surgical procedures and 7 myomectomy. Perioperative and postoperative morbidity was low in all women in our sample.

Conclusion: In our pilot study, myomectomy during pregnancy was safely performed in carefully selected patients, with subserosal or pedunculated leiomyomas that failed to respond to conservative treatment, with low perioperative and postoperative morbidity.

\section{Introduction}

Leiomyomas (fibroids or myomas) are common benign myometrial neoplasms composed of

\section{Zusammenfassung}

$\nabla$

Fragestellung: Hinweise auf spezifische Charakteristika von Frauen mit symptomatischen Leiomyomen während der Schwangerschaft, die sich einer Myomektomie in der Schwangerschaft unterziehen, und solchen, die gut auf eine konservative Therapie ansprechen, sind sehr gering, v.a., weil sie meist aus Fallberichten und Studien mit kleinen Kollektiven stammen. Als erste Studie dieser Art verglich die vorliegende Studie die Charakteristika von konservativ und operativ behandelten Schwangeren.

Material und Methodik: Eine computergestützte Suche aller Behandlungsunterlagen aus unserer Einrichtung vom 1. Januar 2001 bis 31. März 2011 wurde durchgeführt und dabei die International Classification of Diseases (ICD) Codes für Schwangerschaft, Myomektomie und Leiomyome während Schwangerschaft verwendet.

Ergebnisse: 27 Patientinnen wurden unmittelbar wegen Myomen in der Schwangerschaft aufgenommen; 17 der 27 Patientinnen erhielten eine konservative Therapie bei symptomatischen Myomen und 10 unterzogen sich einer Operation: 3 erhielten ein diagnostisches Vorgehen und 7 eine Myomektomie. Die peri- und postoperative Morbidität war niedrig im gesamten Patientinnenkollektiv.

Schlussfolgerung: In unserer Pilotstudie erwies sich die Myomektomie in der Schwangerschaft als eine sichere Methode in einem sorgfältig ausgewählten Patientinnenkollektiv, mit serösen oder gestielten Myomen, die auf eine konservative Therapie nicht angesprochen haben, mit niedriger peri- und postoperativer Morbidität.

smooth muscle [1]. Leiomyomas represent the primary indication for hysterectomy in the United States, Germany, France and England and are estimated to occur in $20-80 \%$ of reproductive-age 
women [2-4]. Leiomyomas can be asymptomatic, but can also cause a variety of symptoms such as menorrhagia, pain, pelvic pressure, and bowel and urinary tract complaints $[3,5,6]$.

Leiomyomas have a prevalence during pregnancy of up to $20 \%$ and they have been associated with an increased obstetric complication rate, such as an increased incidence of spontaneous abortions, fetal malpresentation, intrauterine growth restriction, placenta previa, labor dystocia, placental abruption, retained placenta, preterm labor, premature rupture of membranes, postpartum hemorrhage, and an increased frequency of cesarean sections [7-11]. Nevertheless, little is known about the exact prevalence of leiomyomas in pregnancy and the rate of complications related to or caused by leiomyomas during pregnancy, most of which are asymptomatic $[10,12,13]$.

There is, therefore, no consensus regarding the best approach to the treatment of symptomatic leiomyomas during pregnancy. Conservative treatment is the first option, but the incidence of complications after conservative treatment varies greatly, with rates of up to $38.4 \%[7,14]$. Evidence regarding surgical treatment for symptomatic leiomyomas during pregnancy is sparse and mostly derives from case reports and small patient series $[8,14]$. The present study analyzed a group of women with symptomatic leiomyomas during pregnancy who underwent myomectomy during pregnancy and those treated conservatively.

\section{Methods}

\section{$\nabla$}

We performed a computer search of medical records at the Department of Obstetrics and Gynaecology, University Women's Clinic, Tuebingen, Germany, from 1 January 2001 to 31 March 2011 using the International Classification of Diseases Codes for pregnancy, myomectomy and leiomyomas during pregnancy. This search identified 204 charts, which were retrieved and reviewed. The criterion for inclusion in the study was admission during pregnancy related directly to uterine leiomyomas. If the finding of leiomyoma was incidental to admission, the patient was not included in the study. Patients with first-trimester spontaneous abortions were also not included. All patients had an ultrasound scan on admission; the number and location of the leiomyomas were captured.

Data were coded and entered into an Excel spreadsheet (Microsoft, Redmond, Washington, DC, USA). Statistical analysis was carried out using JMP for Windows, 7.0.1 (SAS Institute, Cary, NC, USA). We report means and standard deviations or medians for continuous variables and frequency counts and percentages for nominal or categorical variables.

\section{Results}

$\nabla$

Twenty-seven patients (out of 204, 13.2\%) were admitted during pregnancy directly related to leiomyomas. All patients received conservative treatment upon admission, consisting of analgesic treatment, antibiotic therapy and tocolytic agents. Conservative treatment was effective in seventeen of the 27 patients $(63.0 \%)$ with symptomatic leiomyomas. Ten patients (37.0\%) had surgery during pregnancy: 3 (11.1\%) had undergone diagnostic surgical procedures and received conservative treatment and 7 (26.0\%) patients underwent myomectomy; indication for surgery were symptomatic leiomyomas during pregnancy that failed to respond to conservative treatment. The patients who had under-
Table 1 Subject characteristics and pathological findings of the two patient groups.

\begin{tabular}{|c|c|c|}
\hline & $\begin{array}{l}\text { Myomec- } \\
\text { tomy group } \\
(n=7)\end{array}$ & $\begin{array}{l}\text { Conserva- } \\
\text { tive treat- } \\
\text { ment group } \\
(n=20)\end{array}$ \\
\hline Age (mean \pm SD) & $34.8 \pm 4.3$ & $31.3 \pm 4.9$ \\
\hline Gestational age at admission (mean \pm SD) & $16.8 \pm 2.5$ & $22.7 \pm 4.6$ \\
\hline Gestational age at delivery (mean \pm SD) & $38.1 \pm 3.9$ & $38.0 \pm 0.3$ \\
\hline \multicolumn{3}{|l|}{ Mode of delivery } \\
\hline Cesarean section, $\mathrm{n}(\%)$ & $6(85.7)$ & $8(47.1)$ \\
\hline Duration hospitalization & $15.3 \pm 9.7$ & $8.7 \pm 6.6$ \\
\hline Diameter largest leiomyoma (mean \pm SD) & $15.5 \pm 4.0$ & $8.7 \pm 2.7$ \\
\hline Total number of leiomyomas (mean \pm SD) & $2.6 \pm 0.9$ & $1.8 \pm 0.9$ \\
\hline \multicolumn{3}{|l|}{ Location largest leiomyoma } \\
\hline - pedunculated/subserosal, n(\%) & $7(100)$ & $5(29.4)$ \\
\hline
\end{tabular}

gone diagnostic surgery were also included in the group of patients with symptomatic leiomyomas during pregnancy who received conservative treatment. The indications for admission, inpatient course, operations, clinical and pregnancy outcomes of the patients were retrieved.

Among the 27 patients admitted with symptomatic leiomyomas during pregnancy, 26 had singleton pregnancies and one patient had a twin pregnancy. Among the twenty patients (74.0\%) with symptomatic leiomyomas during pregnancy from the conservative treatment group; $17 / 20$ (85.0\%) received conservative treatment and 3/20 (15.0\%) received conservative treatment and underwent diagnostic surgery because of symptoms or an uncertain diagnosis. One patient who received conservative treatment was lost to follow-up. Subject characteristics and pathological findings of the two patient groups are listed in $\bigcirc$ Table 1.

Seven patients $(26.0 \%)$ with symptomatic leiomyomas underwent myomectomy during pregnancy ( $\bullet$ Fig. 1, 2 and 3) ( $\bullet$ Table 2). The mean time elapsed between admission and decision to perform surgery was 62.2 hours (range 24.0-120.0 hours). During surgery, 13 leiomyoma specimens were taken; 7 were pedunculated and 6 were subserosal.

Among the 3 women with symptomatic leiomyomas during pregnancy (mean gestational age: 20.0 weeks [range 17.524.4]), who underwent diagnostic surgery, 2 had laparoscopy (one for refractory pain and one for refractory pain and a presumed ovarian mass) and the third underwent exploratory laparotomy for refractory pain and to rule out appendicitis. Myomectomy was not performed in these patients as the lesions were located transmurally and intramurally. All 3 patients had uneventful pregnancies. The patient who underwent laparotomy had a cesarean delivery on request, and the two other patients delivered vaginally at term.

In the group of patients who underwent myomectomy, 6 had preoperative abdominal pain, and 1 had premature labor and abdominal pain. In the group who received conservative treatment for symptomatic leiomyomas, premature labor occurred in 7 (35.0\%) and abdominal pain occurred in 9 (45.0\%); 3 (15.0\%) had both premature labor and abdominal pain, and 1 was admitted for vaginal bleeding.

The mean gestational age at admission in the patients who underwent myomectomy was $16.8 \pm 2.5$ weeks (range 15.0 21.1 ) and $22.7 \pm 4.6$ weeks (range 15.2-33.2) in the patients who received conservative treatment ( $\bullet$ Table $\mathbf{1}$ ). 


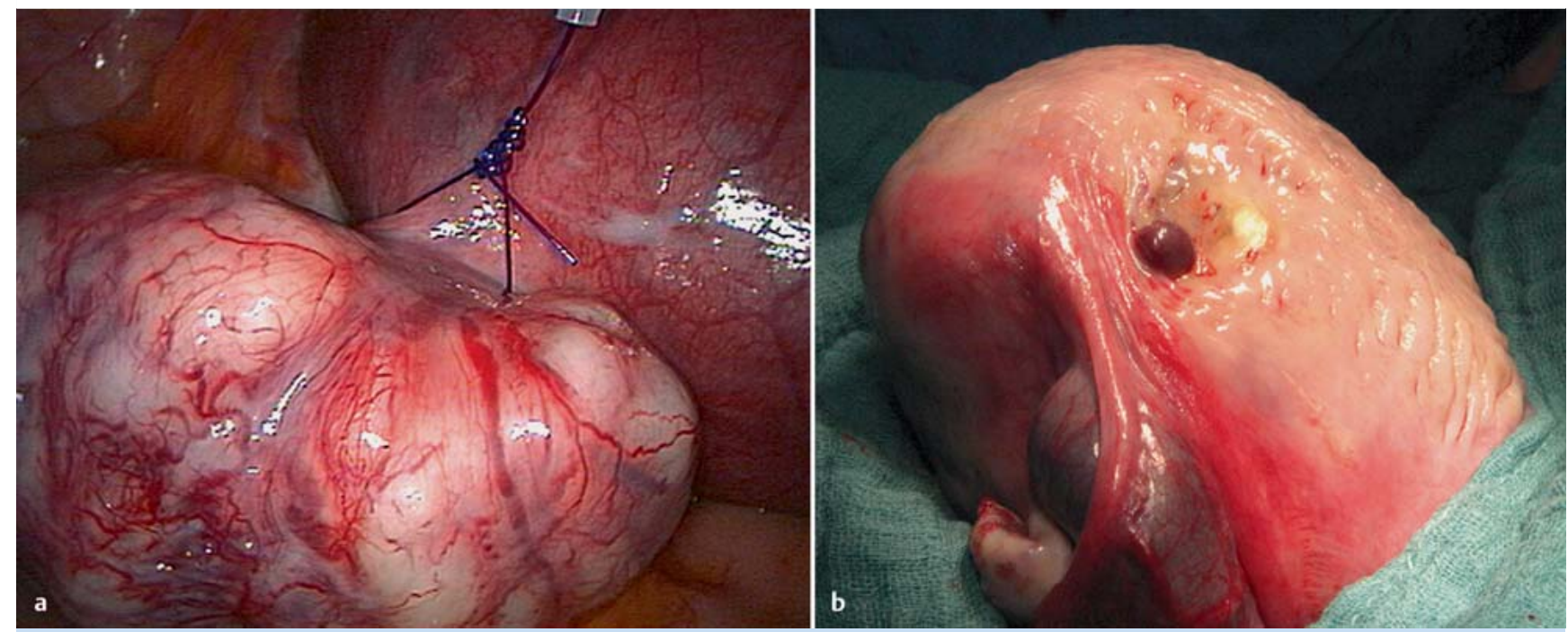

Fig. 1 a and $\mathbf{b}$ Case 1 (see $\bigcirc$ Table 2): a the leiomyoma stalk is grasped during laparoscopy with the Röder-loop; $\mathbf{b}$ uterus after removal of the leiomyoma (image captured during cesarean section).
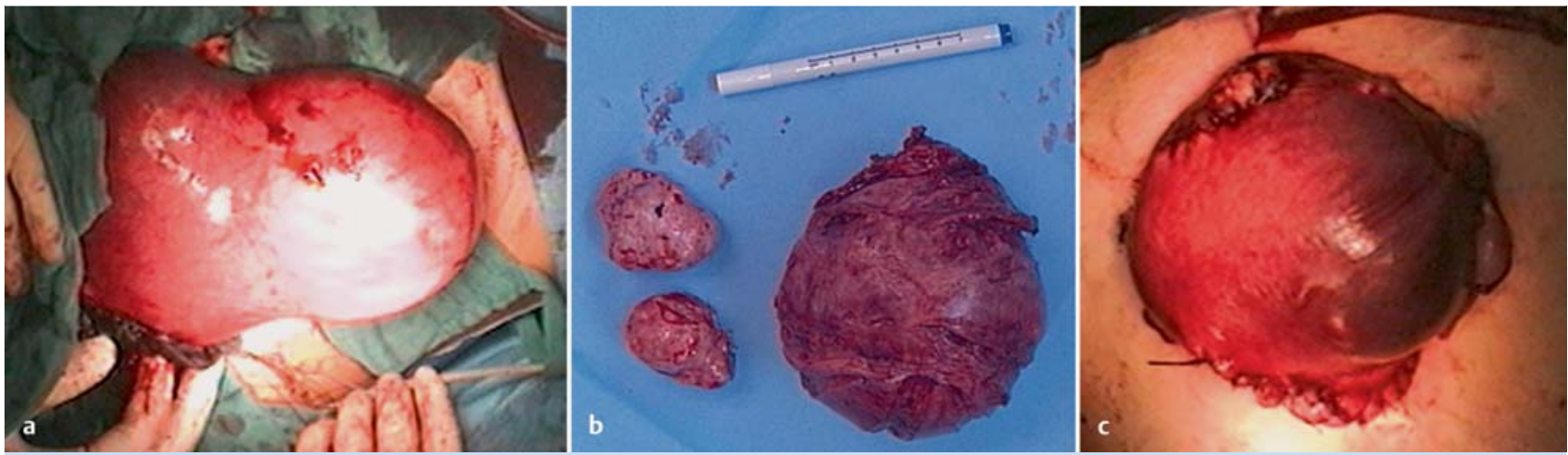

Fig. 2 a to c Case 2 (see $\bigcirc$ Table 2): a intraoperative view of the largest leiomyoma located on the anterior lower uterine segment; $\mathbf{b}$ excised leiomyomas; c uterus after removal of the leiomyomas.
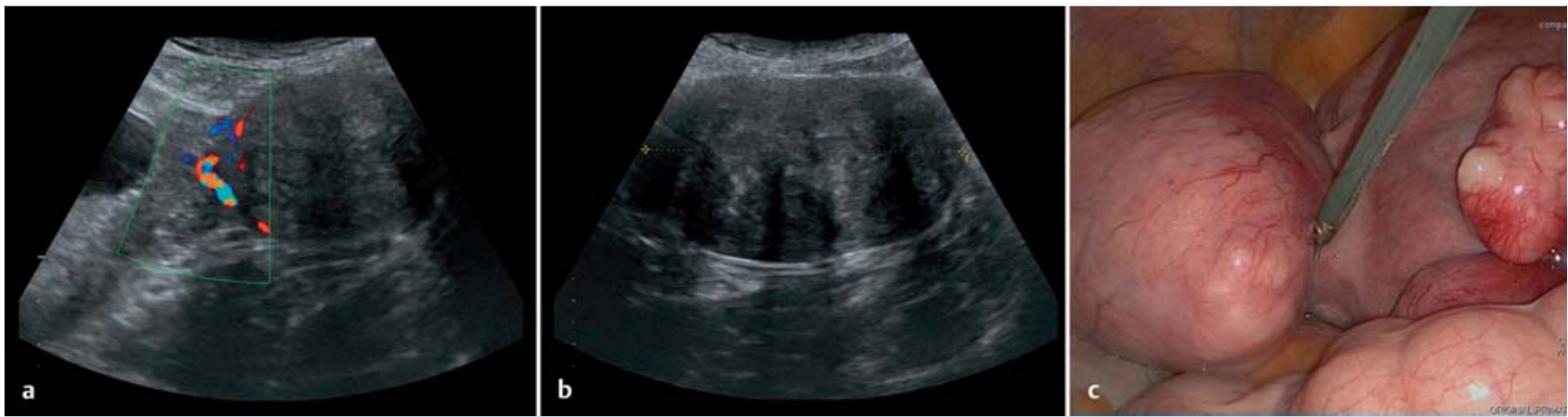

Fig. 3 a to $\mathbf{c}$ Case 7 (see $\odot$ Table 2): a ultrasound view of source of blood flow to the leiomyoma; $\mathbf{b}$ ultrasound view of the uterine mass; $\mathbf{c}$ laparoscopic exposure of the leiomyoma stalk. 


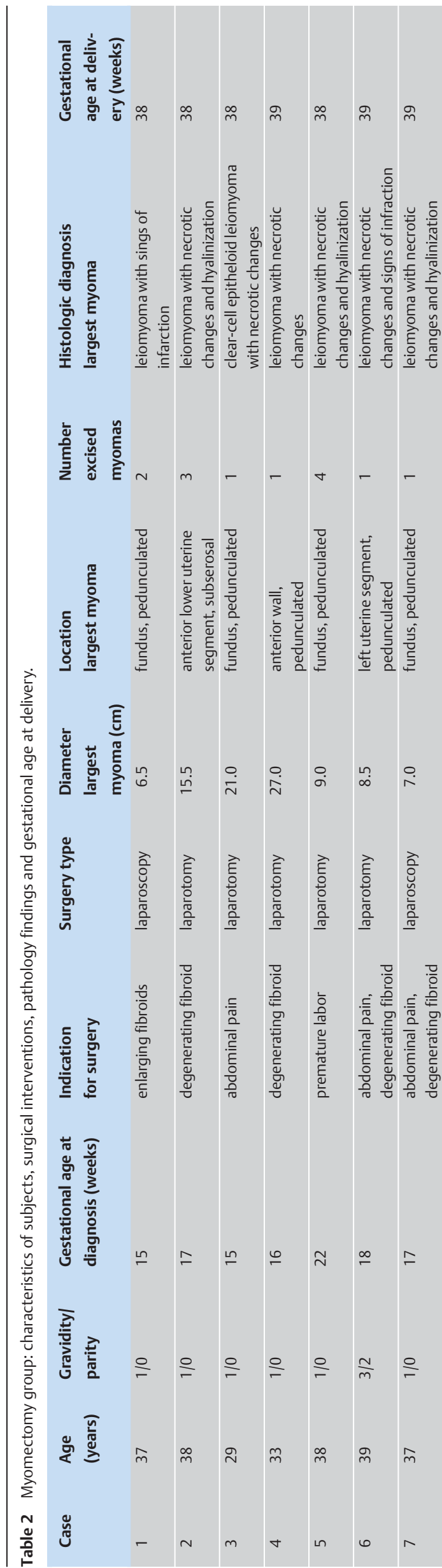

Six patients who underwent myomectomy during pregnancy delivered by cesarean section, while this was the case for 8 of the patients who received conservative treatment ( 8 out of 17 patients; $47.1 \%$ ) for symptomatic leiomyoma ( Table 1 ). One patient from the myomectomy group delivered spontaneously. We recommended a primary cesarean section to one patient from the myomectomy group (14.3\%); the other five patients received a cesarean section on request, with two patients receiving a secondary cesarean section. Gestational age at delivery was $38.1 \pm 3.9$ weeks (range 25.2-41.2) in the myomectomy group and $38.0 \pm 0.3$ weeks (range 37.7-38.5) in the conservative treatment group. Duration of hospitalization was $15.3 \pm 9.7$ days (range 7-26) in the myomectomy group and $8.7 \pm 6.6$ days (range 1-29) in the conservative treatment group ( Table 1). Postpartum hysterectomy was not performed in either group.

Patients who underwent myomectomy had a larger diameter (median $15.5 \mathrm{~cm}$ ) for the largest leiomyoma than those who received conservative treatment (median $7.1 \mathrm{~cm}$ ). All 7 women who underwent myomectomy had pedunculated and subserosal leiomyomas; this was the case in only one third of the women who received conservative treatment; 5/17 women (29.4\%) had subserosal leiomyomas (Table 1). All but one of the 7 patients who underwent myomectomy had histologic signs of degeneration of the largest leiomyoma. Evidence of leiomyoma degeneration at ultrasound was found for only 3 of the 17 women who received conservative treatment. Eight (61.5\%) of the 13 fibroid specimens taken showed necrotic changes, and there was 1 case of clear-cell epitheloid leiomyoma. Regressive changes, hyalinization, and infarction of the leiomyomas had also been reported.

Perioperative and postoperative morbidity was low in all women in our sample. No haemorrhages or surgical infections occurred postoperatively, nor were there any fetal losses after surgery. Relaparotomy on the fourth postoperative day was necessary in one case due to symptoms of intestinal obstruction. Adhesions of the small intestine within the area of the myomectomy scar were found and removed. The further postoperative course of the patient was uneventful and the pregnancy ended with a cesarean delivery at term.

The patient with the twin pregnancy had a $7 \mathrm{~cm}$ fundal intramural leiomyoma and was admitted with premature labor at 22/2 weeks of gestation. She received conservative treatment and suffered a premature rupture of the membranes of the first twin five days after admission. Intrauterine death of the first twin occurred at 24/0 weeks of gestation. Directly after vaginal delivery of the first twin, the pregnancy for the second twin was prolonged by renewed tocolysis. At 25/2 weeks of gestation, cesarean section of the second twin was performed due to pathological antenatal cardiotocography (CTG) recording. A liveborn preterm infant was delivered and the further postoperative course was uneventful.

\section{Discussion}

The present study analyzed a group of women with symptomatic leiomyomas during pregnancy who underwent myomectomy during pregnancy and those treated conservatively. It was interesting to note that most women who underwent myomectomy had leiomyomas with histologic signs of necrosis. Abdominal pain, imaging and histologic signs of necrosis seem to be a common feature in symptomatic leiomyoma in pregnancy and have 
been described in a majority of patients who undergo myomectomy during pregnancy $[7,8,12-16]$.

Some authors advise against myomectomy during pregnancy because of possible perioperative and postoperative complications: hemorrhage, premature rupture of membranes, preterm labor, abortion, and fetal loss [14]. However, in some cases, for example where conservative management fails, the leiomyoma is in a critical location in the lower uterine segment, or, if the diagnosis is uncertain, surgery may be unavoidable [8].

Laparoscopic surgery, also called minimally invasive surgery, has multiple advantages (decreased blood loss, faster recovery and improved visibility) due to the fact that operations in the abdomen are performed through small incisions (usually $0.5-1.0 \mathrm{~cm}$ ) as opposed to the larger incisions needed in laparotomy. Both laparoscopy and laparotomy for removal of symptomatic leiomyomas are considered safe in selected patients during the first and second trimesters of pregnancy [17]. In the present study one patient with a pedunculated leiomyoma underwent laparoscopic myomectomy in the second trimester; the pregnancy progressed to term without further complications. However, regardless of the surgical technique, myomectomy during pregnancy is associated with an increased risk of cesarean section. Thus, consistent with previous data, we found that women who underwent myomectomy for symptomatic leiomyomas during pregnancy had a higher rate of cesarean sections than those treated conservatively $[8,14-16]$.

Several criteria for myomectomy during pregnancy have been proposed. Burton et al. suggested that surgical removal should be limited to pedunculated leiomyomas, whereas Exacoustos and Rosati suggested myomectomy for both pedunculated and subserosal leiomyomas. In our study, one of the largest leiomyomas removed was subserosal, and 5 were pendunculated. Recurrent pain, large or rapidly growing leiomyomas, medium or large leiomyomas located in the lower uterine segment, and leiomyomas in the immediate vicinity of the placenta have been suggested as possible indications for surgery $[8,14-16]$.

Mollica et al. reported a lower incidence of premature labor, premature rupture of membranes and preterm labor in a group of women who underwent elective myomectomy during pregnancy than in a group who received conservative treatment and a control group of pregnant women with no evidence of leiomyomas [16]. The authors concluded that elective myomectomy during pregnancy as a preventative measure before the onset of acute complications is a safe option when done early in carefully selected patients [16]. Nevertheless, the first option in symptomatic patients should always be the conservative treatment of leiomyomas during pregnancy.

Major limitations of this study are the small number of patients included and its retrospective design. Our results therefore need to be interpreted with caution. Nevertheless, patients with large $(>6 \mathrm{~cm})$, symptomatic, subserosal or pedunculated leiomyomas with signs of degeneration that fail to respond to conservative treatment may require myomectomy during pregnancy. Little is known about the relationship between leiomyomas and adverse pregnancy outcomes. Also, the shift in the demographics of maternity will lead to larger proportions of women affected by leiomyomas during pregnancy [9]. Further studies with larger co- horts are therefore required for a better understanding of the risks and benefits of myomectomy during pregnancy.

In our study, myomectomy during pregnancy for symptomatic, subserosal or pedunculated leiomyomas with signs of degeneration that failed to respond to conservative treatment was performed safely in carefully selected patients with low perioperative and postoperative morbidity.

\section{Acknowledgements}

$\nabla$

We thank Alistair Reeves for editing a near-final draft of the manuscript.

\section{Conflict of Interest}

$\nabla$

None.

\section{References}

1 Walker CL, Stewart EA. Uterine fibroids: the elephant in the room. Science 2005; 308: 1589-1592

2 Marshall LM, Spiegelman D, Barbieri RL et al. Variation in the incidence of uterine leiomyoma among premenopausal women by age and race. Obstet Gynecol 1997; 90: 967-967

3 Stewart EA. Uterine fibroids. Lancet 2001; 357: 293-298

4 Fernandez H, Farrugia M, Jones SE et al. Rate, type, and cost of invasive interventions for uterine myomas in Germany, France, and England. J Minim Invasive Gynecol 2009; 161: 40-46

5 David M, Kröncke, T. Uterine fibroid embolisation - potential impact on fertility and pregnancy outcome. Geburtsh Frauenheilk 2013; 73: 247255

6 Scheurig-Münkler C, David M, Kröncke TJ. Uterusarterienembolisation bei Patientinnen mit symptomatischen Gebärmuttermyomen: prospektive Studie zu klinischem Erfolg und Veränderung der Lebensqualität im langfristigen Verlauf. Geburtsh Frauenheilk 2011; 71: 653-658

7 Döring GK, Lärm S. Conservative procedures in 64 pregnant patients with myoma: the course of pregnancy, labor, and the puerperium. Geburtsh Frauenheilk 1987; 47: 26-29

8 Burton CA, Grimes DA, March CM. Surgical management of leiomyomata during pregnancy. Obstet Gynecol 1989; 74: 707-709

9 Laughlin SK, Baird DD, Savitz DA et al. Prevalence of uterine leiomyomas in the first trimester of pregnancy: an ultrasound-screening study. Obstet Gynecol 2009; 113: 630-635

10 Shavell VI, Thakur M, Sawant A et al. Adverse obstetric outcomes associated with sonographically identified large uterine fibroids. Fertil Steril 2012; 971: 107-110

11 Coronado GD, Marshall LM, Schwartz SM. Complications in pregnancy, labor, and delivery with uterine leiomyomas: a population-based study. Obstet Gynecol 2000; 95: 764-769

12 Katz VL, Dotters DJ, Droegemueller W. Complications of uterine leiomyomas in pregnancy. Obstet Gynecol 1989; 73: 593-596

13 Wong L, Ching TW, Kok TL et al. Spontaneous hemoperitoneum from a uterine leiomyoma in pregnancy. Acta Obstet Gynecol Scand 2005; 84: 1208-1209

14 De Carolis S, Fatigante G, Ferrazzani S et al. Uterine myomectomy in pregnant women. Fetal Diagn Ther 2001; 16: 116-119

15 Exacoustos $C$, Rosati $P$. Ultrasound diagnosis of uterine myomas and complications in pregnancy. Obstet Gynecol 1993; 82: 97-101

16 Mollica G, Pittini I, Minganti E et al. Elective uterine myomectomy in pregnant women. Clin Exp Obstet Gynecol 1996; 23: 168-172

17 Sentilhes $L$, Sergent $F$, Verspyck $E$ et al. Laparoscopic myomectomy during pregnancy resulting in septic necrosis of the myometrium. BJOG 2003; 110: 876-878 